\title{
Simulasi Kinerja Siswa Dengan Metode Fuzzy Inference Sugeno Menggunakan Aplikasi Matlab
}

\author{
Halimahtus Mukminna ${ }^{1}$,Devita Maulina Putri ${ }^{2}$, Anik Nur Handayani ${ }^{3}$ \\ Universitas Negeri Malang \\ 1'halimahtus.911@gmail.com,2devitamaulinaputri@gmail.com, ${ }^{3}$ aniknur.ft@um.ac.id
}

\begin{abstract}
ABSTRAK. Tujuan artikel ini adalah membuat simulasi untuk penilaian kinerja siswa menggunakan logika fuzzy untuk mengatasi masalah proses penilaian evaluasi siswa. Disamping itu belum adanya sistem khusus yang dapat mengoptimalkan dalam memberikan dukungan bagi guru dalam melakukan evaluasi yang masih bersifat perhitungan manual. Satu cara penentuan perhitungan hasil evaluasi siswa dapat dipermudah dengan menggunakan bantuan pertimbangan Artifical Intelligence (AI) sebagai optimasinya. Dalam pertimbangan evaluasi kinerja siswa ini menggunakan logika fuzzy dengan metode inference system sugeno. Metode sugeno ini merupakan metode inference fuzzy untuk aturan yang direpresentasikan dalam bentuk IF-THEN, dimana output sistem tidak berupa himpunan fuzzy, melainkan berupa persamaan linier. Kriteria yang digunakan dalam penilaian kinerja siswa meliputi very unsuccesusful, unsuccessful, average, successful, dan very successful. Pada simulasi ini hasil yang ditampilkan dengan perhitungan manual dan perhitungan Matlab sebagai pembandingnya hasil perhitungan secara manual nilai result 45,5 sedangkan pada perhitungan matlab nilai result sebesar 48,5. Sehingga dapat disimpulkan selisih yang disebabkan tingkat akurasi hasil inference rule pada perhitungan manual kurang efektif bahkan terkadang banyak inference rule yang harus disesuaikan.
\end{abstract}

Kata Kunci: Evaluasi, Fuzzy Sugeno, Matlab

\section{PENDAHULUAN}

Perkembangan kehidupan manusia saat ini mengalami kemajuan yang sangat pesat. Perkembangan ini berlaku pada segala aspek seperti ekonomi, sosial, politik terlebih lagi pada bidang teknologi. Seiring dengan kemajuan teknologi informasi dan komunikasi berperan sangat penting dalam kehidupan manusia. Manusia mulai memanfaatkan teknologi seperti komputerisasi dalam membantu pekerjaan maupun kehidupan seharihari. Contoh dalam dunia pendidikan terdapat sistem informasi akademik yang dapat membantu perkiraan guru dalam mengolah nilai dan membantu siswa dalam mengontrol hasil belajarnya. Perkiraan nilai ini yang kerap kali didapatkan dalam bidang kecerdasan buatan seperti logika fuzzy, teknik matematika dari set-teori yang dapat diterapkan untuk berbagai bentuk pengambilan keputusan termasuk penelitian tentang teknik dan kecerdasan buatan.

Saat ini teknologi seperti di atas telah marak dikembangkan pada dunia pendidikan seperti pada seluruh universitas yang ada di Indonesia. Perkiraan hasil evaluasi siswa ini dibutuhkan dan memiliki pertimbangan penilaian tersendiri pada setiap parameternya. Hal tersebut dapat dilihat dari jumlah masukan awal dari evaluasi siswa. Evaluasi siswa yang terjadi saat ini guru haruslah menuliskan secara manual dan mempertimbangkan satu dan lain hal untuk dapat menentukan hasil akhir evaluasi siswa. Seiring perkembangan zaman ditemukanlah cara komputerisasi yang memudahkan guru dalam mengambil keputusan. Teknologi tersebut berawal dari yang berbentuk aplikasi desktop hingga aplikasi yang bersifat online. Namun pada aplikasi atau teknologi yang telah tercipta saat ini ditemukan kelemahan-kelemahan yang dapat berpengaruh pada hasilnya. Terdapat banyak faktor yang mempengaruhi hasil evaluasi siswa seperti nilai-nilai pada saat ujian-ujian yang perlu dipertimbangkan bobotnya.

Penilaian dalam pendidikan seringkali berbentuk nilai numerik yang diperoleh dari hasil penilaian guru terhadap siswa. Untuk itu pada penilaian evaluasi siswa dilihat dari berbagai kriteria pendukung. Hal ini dikarenakan penilaian dan perhitungan adalah bagian terpenting dalam proses pendidikan. Menurut Gokmen (2010) penilaian itu terdapat berbagai metode dalam melakukan evaluasi menggunakan arus, sistem evaluasi klasik, keberhasilan atau kegagalan pendidikan karena itu didasarkan pada pemisahan melalui batas skor tertentu. Seperti contoh pada aplikasi penilaian siswa dalam laboratorium terdapat 50 siswa yang seharusnya dikatakan layak dengan nilai yang memuaskan setelah melakukan pembelajaran pada laboratorium. Pada penerapannya tidak semua siswa dapat dikatakan lulus, hal ini dikarenakan beberapa siswa tersebut tidak dapat memenuhi standar yang ditentukan. Didukung dari penelitian Sakthivel dkk (2013); Patel (2011) dan Upadhya (2012) yang mengusulkan logika fuzzy untuk mengoptimalkan evaluasi kinerja siswa. 
Salah satu cara penentuan perhitungan hasil evaluasi siswa dapat dipermudah dengan menggunakan bantuan pertimbangan Artifical Intelligence (AI) atau kecerdasan buatan sebagai optimasinya. Pertimbangan ini digunakan sebagai salah satu bagian dari ilmu komputer yang mempelajari bagaimana komputer dapat bekerja sebaik apa yang dilakukan manusia atau bahkan lebih. Dalam pertimbangan evaluasi kinerja siswa ini menggunakan logika fuzzy dengan metode inference system sugeno. Menurut Naba (2009), logika fuzzy adalah sebuah metodologi berhitung dengan variabel kata-kata (linguistic variable) sebagai pengganti berhitung dengan bilangan. Sedangkan menurut Kusumadewi (2010) alasan penggunaan metode fuzzy karena konsep ini mudah dimengerti, bersifat fleksibel, memiliki tingkat ketoleransi yang tinggi, mampu memodelkan fungsi nonlinier yang kompleks, serta berdasarkan pada bahasa alami. Pada kesempatan ini penulis mensimulasikan sebuah penilaian evaluasi siswa menggunakan logika fuzzy dengan metode inference system sugeno. Fuzzy metode sugeno merupakan metode inferensi fuzzy untuk aturan yang direpresentasikan dalam bentuk IF - THEN, dimana output (konsekuen) sistem tidak berupa himpunan fuzzy, melainkan berupa konstanta atau persamaan linear (Kusumadewi, 2002:98).Pada simulasi ini hasil yang ditampilkan dengan bantuan Matlab sebagai perhitungannya. Sebagai pembanding akan dilakukan perhitungan manual pula yang terkait dengan sugeno serta menggunakan rumus yang telah ada sebelumnya.

\section{METODE}

Metode yang digunakan dalam pengembangan sistem ini adalah reasoning, yaitu penyelesaian masalah dengan cara mempresentasikan masalah ke dalam basis pengetahuan menggunakan logika atau bahasa formal (bahasa yang dapat dipahami oleh komputer), sedangkan logika yang digunakan adalah fuzzy logic. Pada perhitungan fuzzy logic terhadap tiga tahapan yang harus dilalui, yaitu: (1) fuzzification; (2) inference engine; dan (3) defuzzification(Nugroho, 2010:5).

\section{Fuzzification}

Fuzzification merupakan suatu proses pengubahan nilai tegas atau bersifat pasti (crips input) yang ada ke dalam fungsi keanggotaan. Pada tahap ini yang menjadi crips input adalah nilai dari setiap variabel input yang terdiri dari exam1 (nilai ujian 1) dan exam2 (nilai ujian 2) dan result (sebagai nilai kinerja siswa). Perancangan himpunan fuzzy yang terdiri dari beberapa variabel pada penentuan nilai kinerja siswa di dapatkan dari dua variabel exam1 dan exam2. Sedangkan gambaran hubungan dari variabel input dan output terdapat pada Gambar 1.

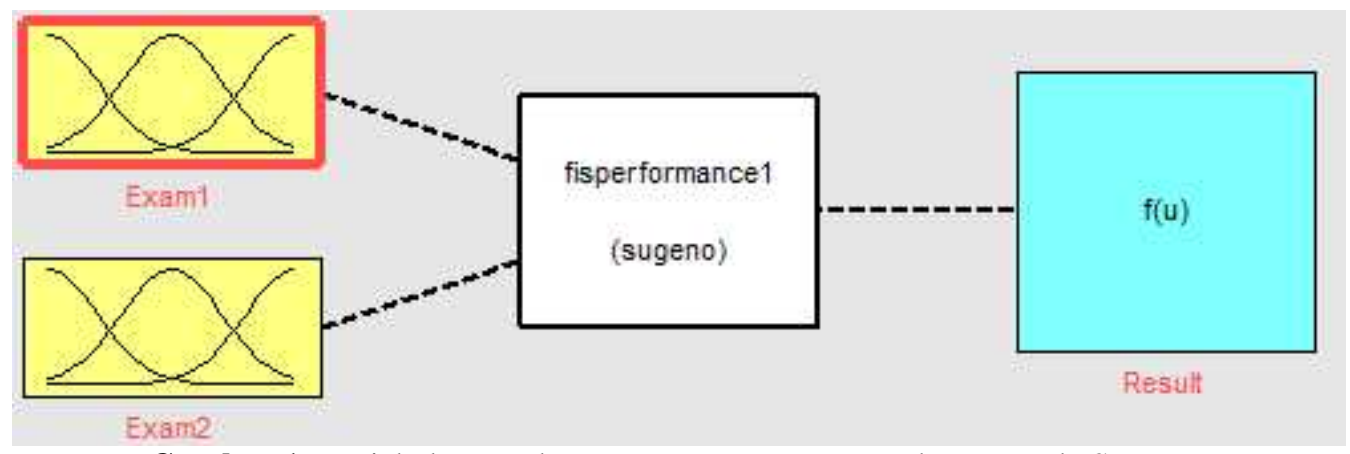

Gambar 1. Variabel Input dan Output yang Menggunakan Metode Sugeno

Tabel 1 Klasifikasi Exam 1 dan Exam 2

\begin{tabular}{|c|c|c|c|}
\hline \multicolumn{3}{|c|}{ Variabel Linguistik } & \multirow{2}{*}{$\frac{\text { Interval }}{(0,0,25)}$} \\
\hline Input & \multirow{5}{*}{ Examl } & Very Low (VL) & \\
\hline & & $\operatorname{Low}(L)$ & $(0,25,50)$ \\
\hline & & Average (A) & $(25,50,75)$ \\
\hline & & $\operatorname{High}(H)$ & $(50,75,90)$ \\
\hline & & Very High $(V H)$ & $(75,90,100)$ \\
\hline & \multirow{5}{*}{ Exam2 } & Very Low $(V L)$ & $(0,0,25)$ \\
\hline & & $\operatorname{Low}(L)$ & $(0,25,50)$ \\
\hline & & Average (A) & $(25,50,75)$ \\
\hline & & $\operatorname{High}(H)$ & $(50,75,90)$ \\
\hline & & Very High (VH) & $(75,90,100)$ \\
\hline Output & Result & Very Unsuccessful (VU) & $(0,0,25)$ \\
\hline
\end{tabular}




$\begin{array}{cc}\text { Unsuccessful }(U) & (0,25,50) \\ \text { Average }(A) & (25,50,75) \\ \text { Successful }(S) & (50,75,90) \\ \text { Very Successful }(V S) & (75,90,100)\end{array}$

Rumus untuk menentukan nilai dari ( menggunakan fungsi keanggotaan segitiga (triangle) yang bisa dilihat pada Gambar 2.

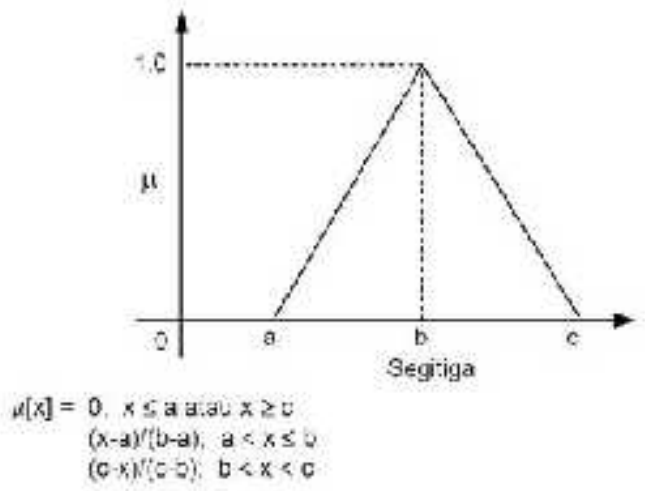

Gambar 2. Rumus Fungsi Keanggotaan Segitiga (Triangle)

Fungsi keanggotaan exam1 dan exam2 memiliki interval yang sama, sehingga kedua exam tersebut memiliki rata-rata set variabel input yang sama yang digambarkan pada Gambar 3 dan Gambar 4 .

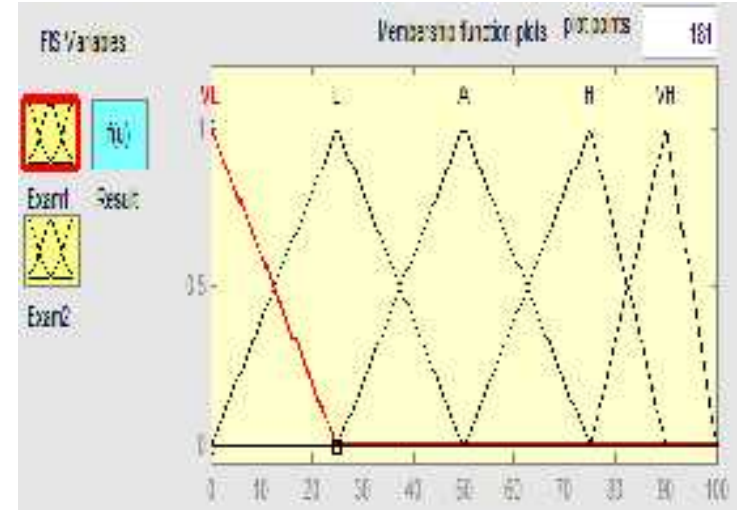

Gambar 3. Membership Function of Examl berdasarkan Simulasi Matlab

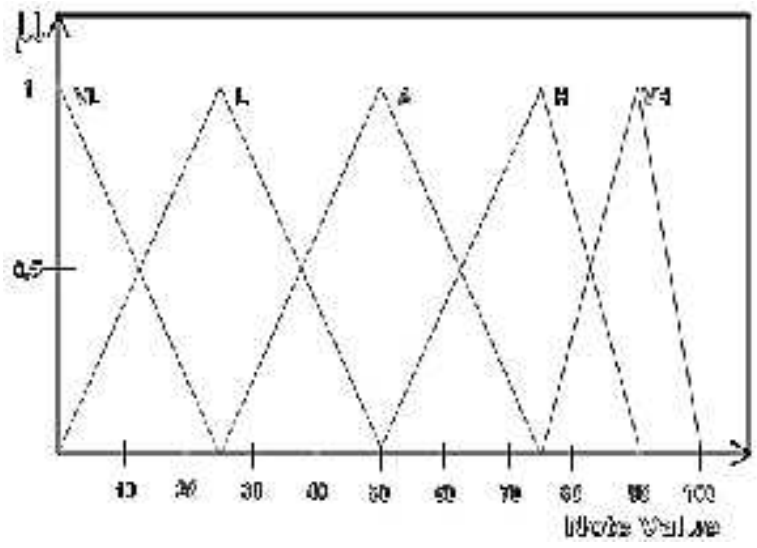

Gambar 4. Membership function of Exam 1 


\section{Inference Engine}

Inference engine dalam menentukan output result (nilai performance) yang didapatkan siswa dengan variabel exam 1 dan exam2. Tedapat 25 rule yang didapatkan, sebagaimana Tabel 2 dalam sistem ini yang digunakan adalah metode MIN, dimana solusi himpunan fuzzy diperoleh dengan cara mengambilan nilai minimum aturan, kemudian digunakan untuk memodifikasi daerah fuzzy, dan mengaplikasikannya ke dalam output dengan menggunakan Operator AND. Jika semua proposisi telah dievaluasi maka output akan berisi himpunan fuzzy yang merefleksikan kontribusi dari tiap-tiap proporsi. Aturan menentukan input dan output fungsi keanggotaan yang akan dalam proses inference yang linguistik dan juga aturan berhak "IF-THAN".

Tabel 2.Inference EngineUntuk Mentukan Nilai Performance Siswa

\begin{tabular}{ll}
\hline$[R 1]$ & IF Exam1 is VL AND Exam2 is VL THEN Result is VU \\
\hline$[R 2]$ & IF Exam1 is VL AND Exam2 is L THEN Result is VU \\
\hline$[R 3]$ & IF Exam1 is VL AND Exam2 is A THEN Result is U \\
\hline$[R 4]$ & IF Exam1 is VL AND Exam2 is H THEN Result is U \\
\hline$[R 5]$ & IF Exam1 is VL AND Exam2 is VH THEN Result is A \\
\hline$[R 6]$ & IF Exam1 is L AND Exam2 is VL THEN Result is VU \\
\hline$[R 7]$ & IF Exam1 is L AND Exam2 is L THEN Result is U \\
\hline$[R 8]$ & IF Exam1 is L AND Exam2 is A THEN Result is U \\
\hline$[R 9]$ & IF Exam1 is L AND Exam2 is H THEN Result is A \\
\hline$[R 10]$ & IF Exam1 is L AND Exam2 is VH THEN Result is A \\
\hline$[R 11]$ & IF Exam1 is A AND Exam2 is VL THEN Result is U \\
\hline$[R 12]$ & IF Exam1 is A AND Exam2 is L THEN Result is U \\
\hline$[R 13]$ & IF Exam1 is A AND Exam2 is A THEN Result is A \\
\hline$[R 14]$ & IF Exam1 is A AND Exam2 is H THEN Result is S \\
\hline$[R 15]$ & IF Exam1 is A AND Exam2 is VH THEN Result is S \\
\hline$[R 16]$ & IF Exam1 is H AND Exam2 is VL THEN Result is U \\
\hline$[R 17]$ & IF Exam1 is H AND Exam2 is L THEN Result is A \\
\hline$[R 18]$ & IF Exam1 is H AND Exam2 is A THEN Result is S \\
\hline$[R 19]$ & IF Exam1 is H AND Exam2 is H THEN Result is S \\
\hline$[R 20]$ & IF Exam1 is H AND Exam2 is VH THEN Result is VS \\
\hline$[R 21]$ & IF Exam1 is VH AND Exam2 is VL THEN Result is A \\
\hline$[R 22]$ & IF Exam1 is VH AND Exam2 is L THEN Result is S \\
\hline$[R 23]$ & IF Exam1 is VH AND Exam2 is A THEN Result is S \\
\hline$[R 24]$ & IF Exam1 is VH AND Exam2 is H THEN Result is VS \\
\hline$[R 25]$ & IF Exam1 is VH AND Exam2 is VH THEN Result is VS \\
\hline &
\end{tabular}

\section{Defuzzyfication}

Input dari proses defuzzifikasi adalah suatu himpunan fuzzy yang diperoleh dari komposisi aturan-aturan fuzzy, sedangkan output yang dihasilkan merupakan suatu bilangan pada domain himpunan fuzzy tersebut yang berupa result yang didapat oleh siswa. Dalam sistem ini yang dipakai adalah infererence sugeno menggunakan defuzzifikasi metode rata-rata terbobot (weighted average) yang dihitung dengan rumus

$$
\mathrm{Z}^{*}=\frac{\sum_{\Gamma}^{\mathrm{h}}-1 \alpha \mathrm{\alpha rZr}}{\sum_{\Gamma}^{\mathrm{R}}-1 \alpha \mathrm{r}}
$$

(Persamaan 1)

dimana zr adalah output pada konsekuen aturan dasar ke-r, $\mathrm{r}$ merupakan fire strength rule ke-r dan $\mathrm{R}$ merupakan banyaknya aturan yang digunakan.

\section{HASIL DAN PEMBAHASAN}

Jika diketahui seorang siswa A mengikuti ujian ke-1 (exam1) mendapatkan nilai 40 dan pada ujian ke-2 (exam2) mendapatkan nilai 65. Dengan kedua nilai yang didapat tersebut akan dihitung jumlah nilai kinerja siswa (student performance).

\section{Perhitungan Manual}

\section{Fuzzyfication}

Fungsi keanggotaan exam $1=40$ ditunjukkan pada Gambar 5 . 


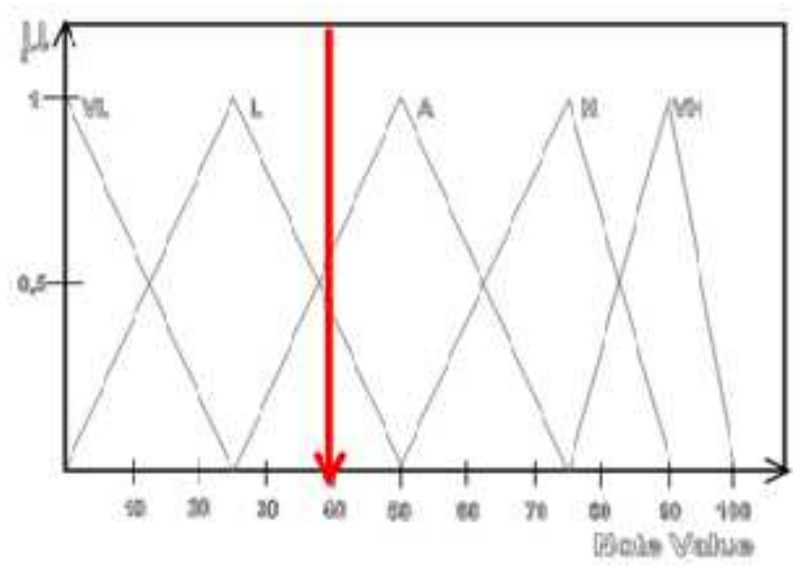

Gambar 5 Fungsi Keanggotaan Exam $1=40$

Perhitungan fungsi keanggotaan Exam $1=40$ terletak dua himpuna fuzzy yaitu Low dan Avarage.

$$
\begin{aligned}
\mu \operatorname{Low}(40) & =\frac{(c-x)}{(c-b)} & \mu \text { Average }(40) & =\frac{(x-a)}{(b-a)} \\
\mu \operatorname{Low}(40) & =\frac{(50-40)}{(50-25)} & \mu \text { Average }(40) & =\frac{(40-25)}{(50-25)} \\
\mu \operatorname{Low}(40) & =\frac{10}{25} & \mu \text { Average }(40) & =\frac{15}{25} \\
& =0,4 & & =0,6
\end{aligned}
$$

\begin{tabular}{|c|c|c|c|c|c|}
\hline $\begin{array}{l}\text { Exam } \\
\text { I/Exam } 2\end{array}$ & VL & $\mathbf{L}$ & $\mathbf{A}$ & H & VH \\
\hline VL & $\begin{array}{c}\text { VU } \\
\text { (R1) }\end{array}$ & $\begin{array}{l}\text { VU } \\
\text { (R2) }\end{array}$ & $\begin{array}{c}\mathrm{U} \\
\text { (R3) }\end{array}$ & $\begin{array}{c}\mathrm{U} \\
(\mathrm{R} 4)\end{array}$ & $\begin{array}{c}\mathrm{A} \\
\text { (R5) }\end{array}$ \\
\hline $\mathbf{L}$ & $\begin{array}{l}\text { VU } \\
\text { (R6) }\end{array}$ & $\begin{array}{c}\mathrm{U} \\
(\mathrm{R} 7)\end{array}$ & $\begin{array}{c}\mathbf{U} \\
(\mathbf{R 8})\end{array}$ & $\begin{array}{c}\text { A } \\
\text { (R9) }\end{array}$ & $\begin{array}{c}\mathrm{A} \\
\text { (R10) }\end{array}$ \\
\hline $\mathbf{A}$ & $\begin{array}{c}\mathrm{U} \\
(\mathrm{R} 11)\end{array}$ & $\begin{array}{c}\mathrm{U} \\
\text { (R12) }\end{array}$ & $\begin{array}{c}\mathbf{A} \\
(\mathbf{R} 13)\end{array}$ & $\underset{(R 14)}{S}$ & $\begin{array}{c}\mathrm{S} \\
(\mathrm{R} 15)\end{array}$ \\
\hline
\end{tabular}

Fungsi keanggotaan exam $2=65$ ditunjukkan pada Gambar 6 .

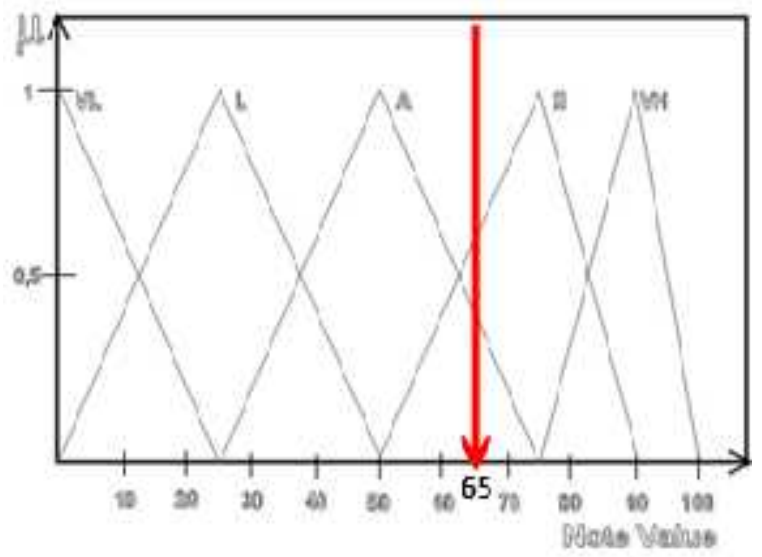

Gambar 6. Fungsi Keanggotaan Examp2 $=65$

Tabel 3. Rule Keanggotaan yang Aktif 


\begin{tabular}{lccccc} 
H & $\mathrm{U}$ & $\mathrm{A}$ & $\mathrm{S}$ & $\mathrm{S}$ & $\mathrm{VS}$ \\
& $(\mathrm{R} 16)$ & $(\mathrm{R} 17)$ & $(\mathrm{R} 18)$ & $(\mathrm{R} 19)$ & $(\mathrm{R} 20)$ \\
VH & $\mathrm{A}$ & $\mathrm{S}$ & $\mathrm{S}$ & $\mathrm{VS}$ & $\mathrm{VS}$ \\
& $(\mathrm{R} 21)$ & $(\mathrm{R} 22)$ & $(\mathrm{R} 23)$ & $(\mathrm{R} 24)$ & $(\mathrm{R} 25)$ \\
\hline
\end{tabular}

Perhitungan fungsi keanggotaan Exam2 = 65 terletak dua himpunanfuzzy yaitu Average dan High.

$$
\begin{aligned}
\mu \text { Average }(65) & =\frac{(c-x)}{(c-b)} & \mu \operatorname{High}(65) & =\frac{(x-a)}{(b-a)} \\
\mu \text { Average }(65) & =\frac{(75-65)}{(75-50)} & \mu \operatorname{High}(65) & =\frac{(65-50)}{(75-50)} \\
\mu \text { Average }(65) & =\frac{10}{25} & \mu \operatorname{High}(65) & =\frac{15}{25} \\
& =0,4 & & =0,6
\end{aligned}
$$

\section{InferenceRule}

Inferencerule yang digunakan

\begin{tabular}{ll}
\hline [R8] & IF Exam1 is L AND Exam2 is A THEN Result is U \\
\hline [R9] & IF Exam1 is L AND Exam2 is H THEN Result is A \\
\hline [R13] & IF Exam1 is A AND Exam2 is A THEN Result is A \\
\hline [R14] & IF Exam1 is A AND Exam2 is H THEN Result is S \\
\hline
\end{tabular}

Dari keempat aturan fuzzy yang digunakan diatas, maka proses inference rule yang digunakan aturan conjunction $\left({ }^{\wedge}\right)$ dengan memilih derajat minimum, sehingga diperoleh.

Pencarian $\alpha$ predikat serta nilai z pada setiap rule:

R8 If Exam 1 is L 0,4 and Exam 2 is $\mathrm{H} 0,4$ then is $\mathrm{U}$

$$
\begin{aligned}
\alpha \text { predikat8 } & =\text { Lower } \cap \text { High } \\
& =\min (\text { Exam } 1 \text { Lower }(40),
\end{aligned}
$$

$$
\begin{aligned}
& \text { Exam2 High(65)) } \\
& =\min (0,4 ; 0,5) \\
& =0,4 \\
& \text { Nilai z8 }=40
\end{aligned}
$$

R9 If Exam 1 is L 0,4 and Exam 2 is H 0,6 then is A

$$
\begin{aligned}
& \alpha \text { predikat9 }=\text { Lower } \cap \text { High } \\
& \text { Exam2 High(65)) } \\
& =\min (\text { Exam1 Lower(40), }
\end{aligned}
$$$$
=0,4
$$

$$
=\min (0,4 ; 0,6)
$$

Nilai z9 $=40$

R13 If Exam 1 is A 0,6 and Exam 2 is A 0,4 then is A

$$
\begin{aligned}
\begin{aligned}
\alpha \text { predikat13 } & =\text { Average } \cap \text { Average } \\
& =\min (\text { Exam1 Average }(40),
\end{aligned} \\
\text { Exam2 Average }(65))
\end{aligned}
$$

$=0,4$

$$
=\min (0,6 ; 0,4)
$$

Nilai $\mathrm{z} 13=65$

R14 If Exam 1 is A 0,6 and Exam 2 is $\mathrm{H} \mathrm{0,6} \mathrm{then} \mathrm{is} \mathrm{S}$

$$
\alpha \text { predikat } 14=\text { Average } \cap \text { High }
$$

Exam2 High(65))

$$
=\min (\text { Exam } 1 \text { Average }(40) \text {, }
$$

$=0,6$

$$
=\min (0,6 ; 0,6)
$$

Nilai z14 = 40 


\section{Defuzzification}

Untuk proses defuzzyfication menggunakan weight average, maka rata-rata nilai performance siswa. Dari penjelasan diatas diperoleh nilai z yaitu :

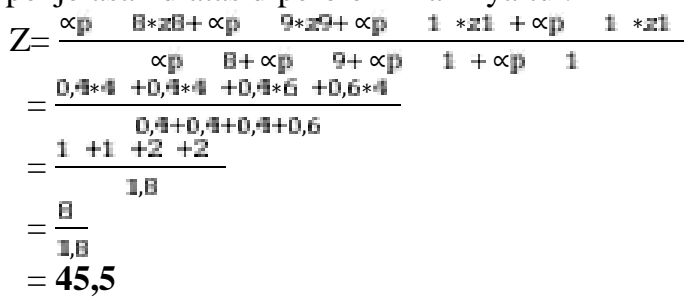

Kesimpulan yang didapat dengan menggunakan model sugeno untuk nilai exam $1=40$ dan $\operatorname{exam} 2=65$, maka nilai performance siswa 45,5.

\section{Perhitungan dengan Simulasi Matlab}

Simulasi program menggunakan aplikasi Matlab. Nilai yang diinputkan sama dengan nilai yang dihitung secara manual untuk mengetahui apakah persamaan atau perbedaan perhitungan secara manual dan perhitungan dengan simulasi menggunakan Matlab.Simulasi perhitungan Matlab terlihat pada Gambar 7.

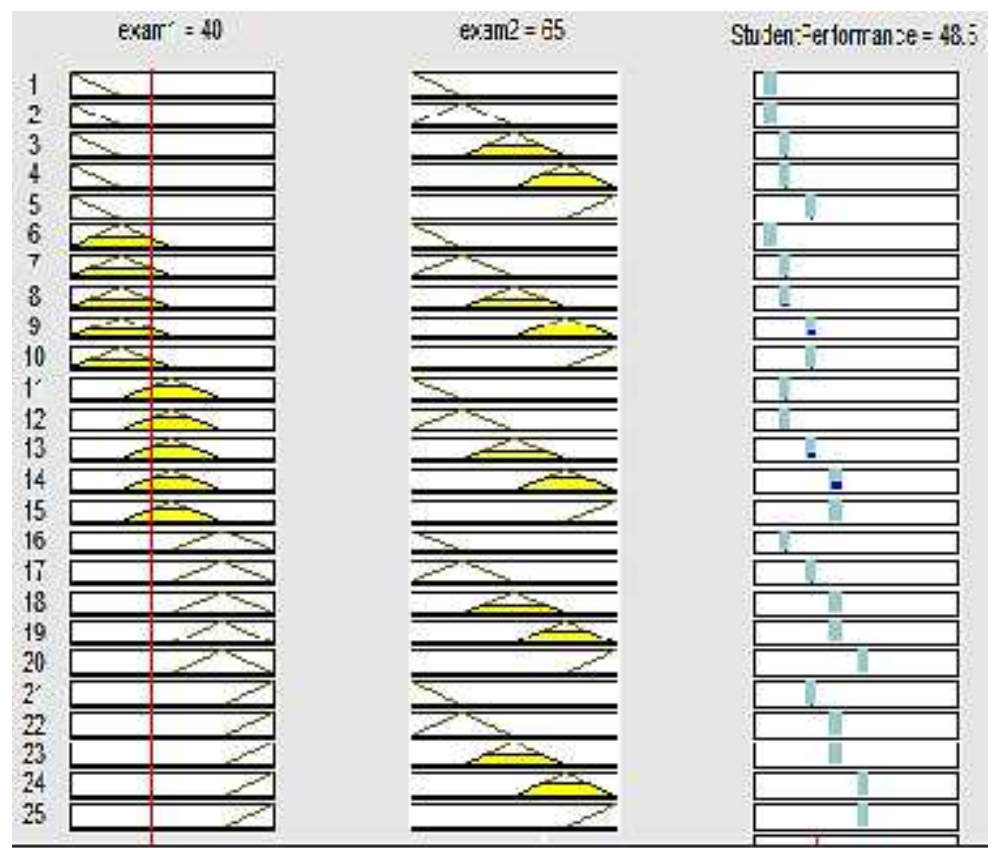

Gambar 7. Rule yang Aktif dan Nilai Result dari Nilai Exam dari 40 dan 65

\section{Analisis}

Rangkuman hasil defuzzification dari kesepuluh perhitungan penentuan evaluasi kinerja siswa menggunakan logika fuzzy dapat dilihat pada Tabel 4.

Tabel 4.Perbandingan Data Hasil Defuzzyfication

\begin{tabular}{|c|c|c|c|c|c|}
\hline \multirow{2}{*}{ Kasus } & \multicolumn{2}{|c|}{ Nilai } & \multicolumn{2}{|c|}{ defuzzyfication } & \multirow{2}{*}{ Selisih } \\
\hline & Exam 1 & Exam 2 & Manual & Matlab & \\
\hline Kasus 1 & 40 & 65 & 45,5 & 48,5 & 3 \\
\hline Kasus 2 & 20 & 55 & 25 & 17,3 & 7,7 \\
\hline Kasus 3 & 70 & 85 & 81 & 95,3 & 14,3 \\
\hline Kasus 4 & 30 & 89 & 56,3 & 58,7 & 2,4 \\
\hline Kasus 5 & 80 & 52 & 84,2 & 80 & 3,6 \\
\hline Kasus 6 & 90 & 22 & 63 & 59 & 4 \\
\hline Kasus 7 & 70 & 72 & 86 & 89 & 3 \\
\hline Kasus 8 & 50 & 65 & 59,8 & 63,1 & 3,3 \\
\hline
\end{tabular}




\begin{tabular}{llllll} 
Kasus 9 & 45 & 75 & 70,4 & 73,6 & 3,2 \\
Kasus 10 & 85 & 59 & 85,9 & 94,7 & 8,8 \\
\hline
\end{tabular}

Berdasarkan tabel 4 dapat diuraikan sebagai berikut: (1) hasil perhitungan manual kasus pertama kinerja siswa didapatkan sebesar 45,5. Sedangkan perhitungan menggunakan matlab sebesar 48,5, selisih antara keduanya sebesar 3; (2) hasil perhitungan secara manual contoh kasus kedua kinerja siswa didapatkan sebesar 25. Sedangkan perhitungan menggunakan matlab sebesar 17,3. Selisih antara keduanya sebesar 7,7; (3) hasil perhitungan secara manual contoh kasus ketiga kinerja siswa didapatkan adalah sebesar 81. Sedangkan pada perhitungan menggunakan matlab adalah sebesar 95,3, selisih antar keduanya sebesar 14,3.

Hasil analisis antara perhitungan manual dengan Matlab menunjukkan selisih yang sedikit jauh, hal ini disebabkan tingkat akurasi hasil inference rule pada perhitungan manual tidak begitu efektif dan efisien, bahkan terkadang banyak inference rule yang harus disesuaikan.

\section{KESIMPULAN}

Dari penjabaran di atas dapat disimpulkan 2 hal, yaitu (1) dalam menentukan kinerja siswa yang dibahas dalam laporan ini menggunakan metode sugeno dengan fungsi implikasi aturan MIN dan defuzzification menggunakan metode weight average, dan (2) berdasarkan hasil pembahasan dan analisis antara perhitungan manual dengan perhitungan Matlab terdapat sedikit selisih yang jauh berbeda, hal ini disebabkan tingkat akurasi hasil parameter pada perhitungan manual tidak begitu efektif dan efisien.

\section{DAFTAR PUSTAKA}

[1] Kusumadewi, Sri. 2002. Analisis Desain Sistem Fuzzy menggunakan Tool Box Matlab. Yogyakarta: Graha Ilmu.

[2] Kusumadewi, Sri \& Purnomo, H. 2010. Aplikasi Logika Fuzzy Untuk Pendukung Keputusan. Yogyakarta: Graha Ilmu.

[3] Gokman, G, etc. 2010. Evaluation of Student Performance in Laboratory using Fuzzy Logic. Procedia Social and Behavioral Science 2, 902-909.

[4] Naba, Agus. 2009. Belajar Cepat Fuzzy Logic menggunakan MATLAB. Yogyakarta: Andi Offset.

[5] Nugroho, A. K. 2010. Pengendali Logika Fuzzy Suhu Hipertermia Berbasis Visual Basic dan Akuasisi Berbasis USB. Prosiding Seminar Nasional Sains dan Teknologi. Semarang, hal. F.1-F.9.

[6] Sakthivel, E, Kannan, S. K \& Arumungan, S. 2013. Optimized Evaluation of Student Performances Using Fuzzy Logic. International Journal of Scientific \& Engineering Research, 4 (9): 1128_-1133.

[7] Patel, S., Sajja, P., \& Pate, A. 2011. Fuzzy Logic based Expert System for Student's Performance Evaluation in Data Grid Environment. International Journal of Scientific \& Engineering Research, 5 (1): $36-40$.

[8] Upadhya, M. M. 2012. Fuzzy Logic Based Evaluation of Performance of Student in Colleges. Journal of Computer Application (JCA), 5 (1): 6-9. 